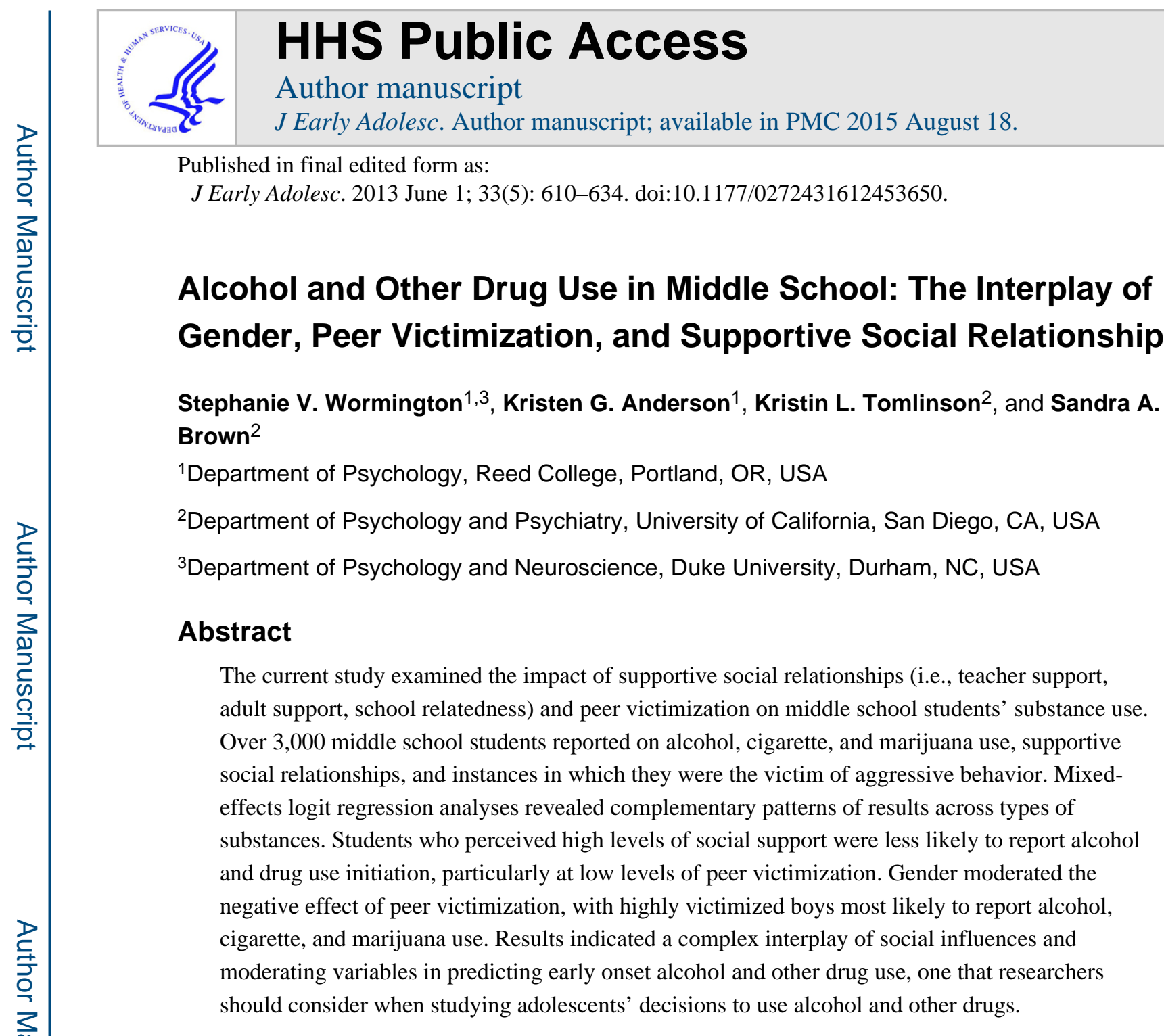

\title{
Keywords
}

peer victimization; gender differences; social support; alcohol; drug use; early adolescence

\begin{abstract}
Early adolescence is an age at which nonfamilial social interactions take on greater importance, influencing students both socially and academically (Rodkin \& Ryan, 2012; Wentzel, 1998). Indeed, relationships with authority figures and peers within academic settings are considered key socializing agents for middle school students (Bandura, 1986; Catalano \& Hawkins, 1996; Reddy, Rhodes, \& Mulhall, 2003). While school is often conceptualized as a positive context—one in which students learn important academic material, form meaningful relationships, and experience positive interactions with teachers -it is also a setting in which youth are likely to witness or experience peer victimization (Card \& Hodges, 2008). Thus, adolescents are exposed to positive and negative social
\end{abstract}

\footnotetext{
Permissions: http://www.sagepub.com/journalsPermissions.nav

Corresponding Author: Kristen G. Anderson, PhD, Department of Psychology, Reed College, 3203 Southeast Woodstock Boulevard, Portland, OR 97202, USA, andersok@reed.edu.

Declaration of Conflicting Interests

The author(s) declared no potential conflicts of interest with respect to the research, authorship, and/or publication of this article.
} 
interactions during the school day, both of which likely have a strong influence on subsequent adjustment and behavior.

Early adolescence is also a time when experimentation with alcohol and illicit substances begins (Johnston, O'Malley, Bachman, \& Schulenberg, 2006). As many as $40 \%$ of eighth grade students report having tried alcohol, with more than $15 \%$ indicating use within the past 30 days (Sullivan, Farrell, \& Kliewer, 2006). Both biological (e.g., neural development; Bava \& Tapert, 2010; Nixon, Morris, Liput, \& Kelso, 2010) and environmental factors (e.g., transition to middle school; Eccles \& Wigfield, 2000) may leave adolescents particularly susceptible to detrimental outcomes associated with substance use and increase the likelihood of serious future problems (e.g., suicide ideation and attempts; Swahn \& Bossarte, 2007; depressive symptoms; Tomlinson \& Brown, 2012). Additionally, research indicates that early initiation of drinking exposes adolescents to delinquent behaviors and can have substantive negative long-term effects (D'Amico, Ellickson, Collins, Martino, \& Klein, 2005; for an exception, see Guttmannova et al., 2011; Peleg-Oren, Saint-Jean, Cardenas, Tammara, \& Pierre, 2009; Swahn \& Donovan, 2005).

The relationship between individual risk or preventive factors and substance use has received considerable scholarly attention. Less studied, however, is the interplay between different types of school-related social factors. If students experience both positive and negative social interactions on a daily basis at school, it is possible that these factors will interact to influence students' decisions to use or abstain from alcohol and drugs. In the current study, we investigated the interplay of supportive social relationships and negative social interactions - mainly, peer victimization - in relation to alcohol, cigarette, and marijuana use in middle school. As early adolescents are strongly influenced by social relationships and spend a significant portion of weekdays in school or affiliated activities (Stearns \& Glennie, 2010), this study focused on social factors within the school community. Gender was also considered given past research highlighting its impact on the interpersonal variables of interest and developmental processes (Perry \& Pauletti, 2011).

\section{Peer Victimization}

Peer victimization is an overarching term that encompasses qualitatively different forms of behavior. One of the most fundamental distinctions made in the victimization literature is between physical and relational forms of victimization. Physical victimization, also referred to as direct or overt victimization, involves being the target of violent actions (e.g., hitting, kicking) or direct verbal threats that are intended to cause harm to others. Physical victimization has been extensively studied in relation to maladaptive outcomes (for a review, see Card, Stucky, Sawalani, \& Little, 2008). Relational victimization, also referred to as covert or indirect victimization, encompasses behaviors (e.g., spreading rumors, withholding friendship) intended to damage others' social relationships (Crick \& Grotpeter, 1995; Feshbach, 1969). The two forms of victimization often exhibit a very high correlation but are considered distinct (Card \& Hodges, 2008). Relational and physical forms of victimization are also considered separately from peer victimization involving bullying. Bullying is distinct from more general acts of aggressive behavior because it involves a repeated, deliberately harmful act and "A power imbalance between the bully and victim" 
(Aalsma \& Brown, 2008, p. 101; Olweus, 2001). As with research on peer victimization, being the victim of bullying can have alarming negative consequences.

Unsurprisingly, peer victimization is often positively associated with early-onset substance use (Nansel, Craig, Overpeck, Saluja, \& Ruan, 2004; Nansel et al., 2001; Tharp-Taylor, Haviland, \& D'Amico, 2009; Topper, Castellanos-Ryan, Mackie, \& Conrod, 2011). Although little work has investigated the mechanisms through which victimization and substance use might be related, several hypotheses have been put forward. For example, research suggests that students experiencing peer victimization do not feel welcome at school, have fewer friends, and receive inadequate support from teachers after being victimized (Boulton \& Underwood, 1992); this overall lack of support may spur adolescents to drink as a way to cope (Nansel et al., 2004). Another possibility is that victimized students use alcohol and substances as a way to cope, a well-documented motive for consuming alcohol (Cooper, 1994). Recent alcohol intervention efforts have been designed to attract high school students with several risk factors, including being bullied or victimized (McGee, Valentine, Schulte, \& Brown, 2011). The current study investigates reports of alcohol and other drug use from middle school students experiencing varying levels of victimization.

\section{Supportive Social Relationships}

Social support in adolescence is crucial for positive adjustment (Eccles \& Wigfield, 2000). As students enter middle school, they begin to seek support from important figures other than parents and immediate family members (Wentzel, 1998). Many of these supportive relationships may be formed at school, where students are exposed to a larger group of same age peers and authority figures than in elementary school (Stipek \& MacIver, 1989). Adolescents may also receive support from nonparental figures outside the school community—such as team coaches, community leaders, or mentors — that could impact success and adjustment (Morgan et al., 2011; Rueger, Malecki, \& Demaray, 2010). In the current study, we considered three potential sources of social support: teachers, school relatedness, and adults outside the school community. These three sources were selected because they represent school support at the individual (i.e., teacher support) and community (i.e., school relatedness) level, as well as support received outside the home and school environments (i.e., adult support).

Due to their position of authority and time spent with students in the classroom, teachers are in a unique position to impact students' beliefs and behavior. In a recent special issue of Journal of Applied Developmental Psychology, researchers noted the critical, far reaching impact teachers have on their students (Kindermann, 2011). This impact may occur directly (Wentzel, 1998) or indirectly, such as influencing students' experiences with peers (Farmer, Lines, \& Hamm, 2011). Numerous studies have identified a positive association between student-teacher relationships and outcomes as wide ranging as self-efficacy, socioemotional adjustment, self-esteem, self-regulation strategies, academic achievement, well-being, relatedness, school adjustment, and help-seeking behavior in early adolescence (Goodenow, 1993; Patrick, Ryan, \& Kaplan, 2007; Wentzel, Battle, Russell, \& Looney, 2010). 
Students may also receive support from a general sense of membership within the school community. School relatedness-referred to by a number of labels including school belonging and school connection-has been defined in numerous ways; at the heart of the concept, however, is a sense that one is a part of and feels comfortable in an educational institution (Oelsner, Lippold, \& Greenberg, 2011). Like teacher support, school relatedness has been linked to positive academic outcomes in myriad studies (Eccles \& Midgley, 1989; Furrer \& Skinner, 2003; Wentzel, 1997), as well as decreased reports of problem behavior (Bryant, Schulenberg, Bachman, O’Malley, \& Johnston, 2000).

While school is a key socializing agent, adolescents also engage in meaningful activities within their community. These out of school contexts, ranging from extracurricular activities and youth involvement groups to interactions with a mentor, hold the potential to impact students' beliefs and behavior. For example, Larson and his colleagues have advocated for the importance of youth programs and extracurricular activities in positive youth development (Larson \& Angus, 2011). Within these contexts, students are likely to form close relationships with adults, who might then impact their behavior and decision-making processes (Rhodes, Grossman, \& Resch, 2000). Such relationships may be particularly important for high risk adolescents (Beier, Rosenfeld, Spitalny, Zansky, \& Bontempo, 2000), including students in the present study who were targets of peer victimization.

\section{Interactions Between Peer Victimization, Supportive Social Relationships, and Gender}

The influence of peer victimization on decisions to use may depend on accompanying levels of social support. In fact, researchers have specifically warned against isolating peer victimization "From other variables with which it is complexly inter-related" (MurrayHarvey \& Slee, 2010, p. 290). Given that one rationale for the association between peer victimization and substance use is a lack of social support (Boulton \& Underwood, 1992), it may be fruitful to consider peer victimization in conjunction with supportive social relationships when attempting to understand adolescent substance use. Numerous studies have documented a relationship between reports of peer victimization and school-related social support. For example, school relatedness is related to peer victimization (Denny et al., 2011; O’ Brennan \& Furlong, 2010), with some data suggesting that victims receive less social support than students who are not victimized (Pouwelse, Bolman, Lodewijkx, \& Spaa, 2011). In fact, a recent article identified school and community climate as the greatest contextual predictors of victimization (Cook, Williams, Guerra, Kim, \& Sadek, 2010).

To better understand the complex interplay of individual, interpersonal and contextual factors underlying students' decisions to use alcohol and other drugs, the associations between social relationships, adjustment, and relevant moderators should be examined. Moderators are crucial to include when investigating substance use, as interventions focusing on certain risk or preventive variables may reduce drinking and substance use only for specific groups of individuals. In the current study, we examined the role of gender in substance use. Past research points to differences between boys and girls in rates of use in early adolescence (Swahn \& Bossarte, 2007), with boys more likely than girls to report drinking and use of other illicit substances. 
Gender differences may also impact relations between peer victimization, supportive social relationships and adjustment. While boys and girls both experience peer victimization, they often interpret and attribute being victimized to different factors (Pronk \& ZimmerGembeck, 2010). For example, studies suggest that girls tend to ruminate about and report more distress from being victimized than boys (Paquette \& Underwood, 1999), as well as expect to hold a grudge against an aggressor for a longer period of time (Prinstein \& Cillessen, 2003). The ways in which boys and girls react to being victimized may very well influence the consequences of peer victimization; it is possible, for instance, that girls' increased feelings of distress in response to being victimized (Paquette \& Underwood, 1999) may leave them more susceptible to alcohol and drug use as a means of coping.

Research also suggests that boys and girls may differ in how they perceive and utilize nonfamilial social support. Studies examining sources of social support other than parents and friends is somewhat limited (Rueger et al., 2010), but generally suggests lower perceived support from teachers and school personnel for boys than girls (Rueger et al., 2010; Rueger, Malecki, \& Demaray, 2008), perhaps because adolescent girls are more likely than boys to seek out social support as a way to cope with stress (Eschenbeck, Kohlmann, \& Lohaus, 2007). Extant research, however, provides a somewhat inconsistent message concerning gender differences in the link between social support and positive adjustment. Higher perceived teacher and school support has been associated with more adaptive functioning for girls but not boys (Wall, Covell, \& MacIntyre, 1999), as well as for boys but not girls (Lifrak, McKay, Rostain, Alterman, \& O'Brien, 1997). Taken together, evidence concerning gender differences in the experience of social support and peer victimization strongly suggests that gender should be considered here.

\section{Current Study}

Given the interrelationships between gender, supportive social relationships, and peer victimization, it is clear that each of these variables cannot be considered in isolation. Investigation of their connection to adolescent drinking and drug use must probe for interactions between variables. The present study examined peer victimization, supportive social relationships (i.e., school relatedness, teacher support, adult support), and gender in relation to middle school students' use of alcohol, cigarettes, and marijuana. Of particular interest was how peer victimization and perceptions of social support might interact to impact students' decisions to use, as well as whether gender would moderate these relationships. Based on past research, supportive social relationships were expected to be associated with lower likelihood of substance use, while associations between peer victimization and increased likelihood of substance use were anticipated. Given the dearth of past research exploring interactions between the variables of interest in relation to alcohol and substance use, no specific hypotheses involving interaction effects were made.

However, gender was expected to moderate the relationship between peer victimization or social support and substance use given past research noting gender differences in substance use, rates of victimization, and perceptions of social support. 


\section{Method}

\section{Participants and Procedure}

Participants were 3069 seventh- and eighth- grade students (age $=12-15$ years) attending one of four public schools that comprised a socioeconomically and culturally diverse school district in San Diego, CA, USA. A sizable proportion of the sample (16-36\%) was represented by each of the four schools from which participants were recruited. The sample was fairly evenly distributed across gender (51.2\% female) and year (51.2\% seventh grade), and students were mostly born in the United States (86.4\%). Participants were predominately Caucasian (64.8\%) but also identified as Black/African American (3.3\%), Hispanic/Latino (16.4\%), Asian American (19.2\%), Native Hawaiian/Pacific Islander (3.1\%), American Indian/Alaskan native (4.6\%) or another racial or ethnic group (16.4\%), with the possibility of identifying as more than one race or ethnicity.

In this study, participants were recruited as part of the California Healthy Kids Survey (California Healthy Kids Survey[CHKS], 2009). Parents were notified of the study electronically and could contact schools if they did not wish for their child to participate (99\% consent rate). Approximately 95\% of students consented to take the survey. Participants were asked to fill out anonymous self-report questionnaires, including the questions in this study, during regular school hours after being given instructions by a trained research staff member. Approval was received from the University of California, San Diego Committee for the Protection of Human Subjects, as well as participating schools.

\section{Measures}

All questions were drawn from the CHKS-Middle School 2009 Version (West Ed, 2009).

Demographic variables-Gender and school were recorded for all students.

Peer victimization-Items on peer victimization assessed two types of victimization: general victimization and bullying victimization (McGee et al., 2011). Questions assessing general victimization $(n=8)$ asked how many times on school property students had experienced a number of victimization situations. Items represented both physical victimization (e.g., been pushed, shoved, slapped, hit, or kicked by someone who wasn't just kidding around; been threatened or injured with a weapon [gun, knife, club; etc.]) and relational victimization (e.g., had mean rumors or lies spread about you; been made fun of because of your looks or the way you talk). Questions assessing being the victim of bullying $(n=6)$ asked how many times on school property students had been bullied for a number of reasons, specifying that "You were bullied if repeatedly shoved, hit, threatened, called mean names, teased in a way you didn't like, or had other unpleasant things done to you. It is not bullying when two students of about the same strength quarrel or fight" (emphasis original). Students reported on the frequency with which they were bullied because of their race/ ethnicity/national origin, religion, gender, sexuality, physical or mental disability, or any other reason. All victimization questions were answered on a 4-point Likert-type scale ( $1=0$ times, $4=4$ or more times). 
Prior to testing research hypotheses, an exploratory factor analysis was run on peer victimization items. All items loaded on to a single factor, with loadings greater than .41. The second factor had an eigenvalue less than one, and when a two-factor solution was examined all items still loaded more strongly on to the first factor. This finding held for analyses run with the entire sample and separately by gender. As a result, all peer victimization items were collapsed in to a single composite variable representing general peer victimization. It should be noted that, while all items loaded on to a single factor in the present study, items relating to verbal forms of relational victimization as conceptualized in the current study (e.g., being made fun of for sexual preference or looks) are not always considered to be instances of peer victimization.

Supportive social relationships-To assess school relatedness, participants responded to questions from the School Connectedness scale concerning how close they felt to the school community ( $n=5, a=.78$; for example I feel close to people at this school; I feel like I am a part of this school) on a 5-point scale $(1=$ strongly disagree, $5=$ strongly agree $)$. Questions measuring perceived teacher support $(n=6, a=.86$; e.g., there is a teacher or other adult at school who really cares about me; there is a teacher or other adult at school who listens to me when I have something to say) and perceived adult support ( $n=5, a=$. 92; e.g., outside of my home and school, there is an adult who always wants me to do my best; outside of my home and school, there is an adult who believes I will be a success) were drawn from the Caring Relationships subscale. Teacher and adult support were both measured on a 4-point scale $(1=$ not at all true, $4=$ very true $)$.

Use variables-Participants reported their use of alcohol, cigarettes, and marijuana during their lifetime, measured using items drawn from the Monitoring the Future Study survey (Anderson \& Brown, 2011; Johnston, O’Malley, Bachman, \& Schulenberg, 2010). Students were asked how many times in their lives they had used or tried a particular substance and prompted to answer on an 8 -point scale $(1=0$ times, $8=$ over 50 times $)$. Due to low base rates of use, unsurprising given the sample age, all use variables were dichotomized (0/1), so that a value of 0 indicated no use and a value of 1 indicated any or some use.

\section{Results}

Due to the sample size and number of analyses run in the present study, we used a significance criterion of $p<.01$ for omnibus tests to minimize the likelihood of Type 1 errors. Two percent of data from the independent variables was missing within this data set. Multiple imputation was used to compensate for patterns of missing data among predictors within the regression analyses (MI; Baraldi \& Enders, 2010). Using mi impute in Stata 12.0 (StataCorp LP, College Station, TX), each missing value was replaced by a set of $\mathrm{m}>1$ plausible values to generate 50 data sets. Imputation equations used alcohol, cigarette, and marijuana use as predictors for the independent variables, and interaction terms were passively imputed from the estimated values. Subsequently, estimates for each set were combined to provide parameter estimates and standard errors in the regressions (Anderson, Tomlinson, Robinson, \& Brown, 2011). 


\section{Correlations and Descriptive Statistics}

Using the available data, correlations for all predictor variables are presented in Table 1. In line with past research, all supportive social relationship factors were positively correlated with one another and negatively correlated with reports of peer victimization. Independent sample $t$-tests revealed gender differences on all predictor variables; girls reported greater levels of school relatedness, $t(3060)=-8.33, p<.0001$, teacher support, $t(3058)=-7.98, p$ $<.0001$, and adult support, $t(3052)=-4.86, p<.0001$, and lower rates of peer victimization, $t(3008)=6.51, p<.0001$, than boys. These gender differences are consistent with past research (Simons-Morton, Crump, Haynie, \& Saylor, 1999; Xie, Drabick, \& Chen, 2011).

In the sample, $20.3 \%$ of participants reported any or some use of alcohol, $8.6 \%$ reported use of cigarettes, and $6.5 \%$ reported use of marijuana. Participants who acknowledged past substance use reported varying frequency of use, ranging from trying the substance one or two times to more than 50 lifetime uses. Gender differences were found for use of cigarettes, $\chi^{2}(d f=1)=4.37, p=.04$, and marijuana, $\chi^{2}(d f=1)=10.90, p<.0001$, but not for alcohol, $\chi^{2}(d f=1)=1.37, p=.24$. Boys were more likely to report any or some use of cigarettes or marijuana, but not alcohol, than girls.

\section{Mixed-Effects Logit Regression Analyses}

A series of mixed-effects logit regression analyses were run to examine the influence of supportive social relationships (school relatedness, teacher support, and adult support), gender, and peer victimization on substance use. Logit models were considered appropriate given the low baseline rate of use within the sample, and our interest in identifying youth who initiated use at an early age. All analyses were run using the mi estimate: xtmelogit command in Stata 12.0 (StataCorp LP, College Station, TX). To compare the influence of different types of social support, three separate regressions were run per substance examining one of the three types of supportive social relationships. Given that school-related factors were examined as independent variables in the present study, and past research identifies school factors as a crucial predictor of substance use (Ennett, Flewelling, Lindrooth, \& Norton, 1997), school was included as a random effects parameter in analyses. All independent variables were centered prior to analysis (Aitken \& West, 1991).

The interactions among gender, peer victimization, and supportive social relationships were of particular interest in the present study. Therefore, statistically significant interactions between variables were probed using code in $R$, accounting for the random effects (www.quantpsy.org/interact/hlm2.htm; Preacher, Curran, \& Bauer, 2006). Simple intercepts and slopes were evaluated at conditional values and region boundaries, and plotted visually to aid in interpretation. In cases of interactions between two continuous variables, one variable was plotted at one standard deviation below the mean, the mean (0), and one standard deviation above the mean. Results of all mixed-effects regression analyses are presented in Tables 2, 3, and 4 .

Alcohol use-Results for alcohol use are presented in Table 2. School emerged as a statistically significant random effects parameter in all three regression analyses $\left(\chi^{2}=20.49\right.$ -22.21 ; intraclass correlations $=.02-.02$ ). A gender $\times$ peer victimization interaction 
emerged across all regressions for alcohol use, as well. While the relationship between peer victimization and alcohol use was significant for girls $(b s=0.07-0.08, z s=7.83-9.04, p<$. $0001)$ and boys $(b=0.12-0.13, z s=7.17-26.83, p<.0001)$, the effect was stronger for boys at the highest levels of victimization. The likelihood of drinking was no greater for boys at average levels of peer victimization, but boys were less likely to have consumed alcohol than girls at low levels of peer victimization. Main effects of school relatedness and teacher support were qualified by a two-way social relationship $\times$ peer victimization interaction. Post hoc analyses indicated that, although high reported school relatedness and teacher support were associated with lower likelihood of alcohol use at high ( $b s=-0.36-$ $0.50, z s=-4.39-5.08, p<.0001)$, moderate $(b s=-0.50-0.64, z s=-5.59-6.40, p<.0001)$, and low $(b s=-0.64-0.78, z s=-5.20-5.80, p<.0001$ ) levels of victimization, they had the greatest impact when peer victimization was low. There was also a main effect of adult support; consistent with hypotheses, higher levels of perceived adult support predicted lower likelihood of alcohol use.

Cigarette use-Results of analyses for cigarette use are presented in Table 3. Again, school emerged as a statistically significant random effects parameter in regression analyses for all three types of supportive social relationships $\left(\chi^{2}=13.46-19.96\right.$; intraclass correlations $=.05-.06)$. Similar to alcohol, a gender $\times$ peer victimization interaction emerged when school relatedness, teacher support, and adult support were included in separate analyses. Post hoc probing suggested that peer victimization conferred greater risks for smoking for boys $(b s=0.07-0.09, z s=4.50-9.04, p<.0001)$ and girls $(b s=0.12-0.15$, $z s=5.67-15.00, p<.0001$ ), but the effect was stronger for boys; boys were less likely than girls to smoke at low levels of peer victimization but were more likely to have smoked a cigarette when endorsing high levels of peer victimization. There was also a two-way interaction between school relatedness and peer victimization. Analogous to the interaction for drinking, school relatedness exhibited a negative relationship with smoking at high $(b=$ $-0.08, z=-4.29, p<.0001)$, moderate $(b=-0.09, z=-4.50, p<.0001)$, and low levels of peer victimization $(b=-0.11, z=-4.26, p<.0001)$, but had its greatest influence at lower levels of victimization. Finally, there were main effects for teacher support and adult support, with higher levels of both related to less likelihood of smoking.

Marijuana use-Marijuana use results are presented in Table 4. As with analyses for alcohol and cigarette use, school was a statistically significant random effects parameter in all analyses $\left(\chi^{2}=22.75-29.37\right.$; intraclass correlations $\left.=.05-.06\right)$. Main effects of gender and peer victimization were qualified by a gender $\times$ peer victimization interaction for school relatedness, teacher support, and adult support. Results followed the same pattern as that found for alcohol and cigarettes: higher levels of victimization were associated with greater endorsement of prior marijuana use for boys ( $b s=0.13-0.14, z s=6.28-14.00, p<.0001$ ) and girls ( $b s=0.07-0.08, z s=7.00-8.00, p<.0001$ ), but the effects were stronger for boys; girls reported greater likelihood of marijuana use than boys when peer victimization levels were low. In addition, a gender $\times$ teacher support interaction emerged. Greater teacher support was associated with a lower likelihood of marijuana use for boys $(b=-1.22, z=$ $-2.49, p=.01)$ more so than girls $(b=-0.63, z=-3.64, p<.001)$. Finally, there was a main 
effect of school relatedness. As hypothesized, greater school relatedness was associated with less likelihood of marijuana use.

\section{Discussion}

From the results of the current study, it is clear that social interactions outside of the home relate to middle school students' substance use. Further, two-way interactions between social variables and students' gender suggest that the process by which these factors are associated with alcohol and other drug use is not uniform across individuals. As a result, care must be taken in future studies not only to explore the direct relations between preventive and risk factors and substance use, but also to acknowledge the interplay of these factors and key moderating variables.

Consistent across analyses was a two-way interaction between gender and peer victimization. For all substances, boys who reported high levels of peer victimization were most likely to report any or some alcohol or drug use. Notably, all peer victimization items loaded on to a single factor, despite representing what the literature has identified as distinct forms of victimization (Crick \& Grotpeter, 1995). This finding is perhaps less surprising when considering the high correlation between relational and physical forms of victimization found in past studies (Card et al., 2008). However, as peer victimization in the present study represents an overarching measure of victimization, caution should be exercised when interpreting these results.

Highly victimized boys were most at risk for early onset substance use, suggesting that these students are optimal targets for peer victimization interventions. Given the results of the present study and qualitative evidence that victimized middle school boys often experience both relational and physical forms of victimization (Pronk \& Zimmer-Gembeck, 2010), evidence-based interventions that target multiple forms of victimization may be most effective in deterring the initiation of substance use. Interventions specifically designed to target relational victimization have only recently been enacted in schools with varying rates of success (Leff, Waasdorp, \& Crick, 2010). Further research is needed to substantiate this suggestion.

Several victimization-focused interventions (e.g., You can't say you can't play; Harrist \& Bradley, 2003; Leff et al., 2010) actively seek to change the school environment. Similarly, a number of alcohol and drug interventions have targeted the school climate and generally been equally effective for both boys and girls (Oelsner et al., 2011; Sznitman, Dunlop, Nalkur, Khurana, \& Romer, 2011). In the present study, several two-way interactions between peer victimization and supportive social relationships were identified. Specifically, peer victimization interacted with teacher support and school relatedness in relation to alcohol use and with school relatedness for cigarette use. These supportive social relationships, however, seemed to have the greatest impact when peer victimization was low, suggesting a less pronounced, but still significant, impact for highly victimized students. Interesting as well, is that adult support-that is support from adults outside of the home and school — did not interact with peer victimization in any of the analyses. Although at risk youth are often enrolled in youth activities or mentoring programs to discourage 
problem behavior, evidence concerning the effectiveness of these approaches has been inconclusive (Lubans, Plotnikoff, \& Lubans, 2012). While supportive social relationships are associated with lower likelihood to use substances, they have less impact on children with greater victimization experience - those at greatest risk of drinking or using substances.

As initially hypothesized, supportive social relationships were associated with lower likelihoods of alcohol and other drug use. Somewhat surprisingly, gender did not moderate the relation between preventive variables and substance use, with the exception of an interaction between gender and teacher support for marijuana use. Different social support systems emerged as protective depending on the agent being examined, highlighting the importance of considering alcohol, cigarette, and marijuana use as related but distinct outcomes. The lack of statistically significant interactions for supportive social relationships with gender, coupled with the main effects of adult support on alcohol use and school relatedness on marijuana use, suggest that fostering supportive social relationships is associated with lower likelihood of alcohol and other drug use for both boys and girls in middle school.

\section{Implications and Suggestions for Future Research}

Taken together, these results may have important implications not only for researchers but also for educators and policy makers. Findings suggest that attempts to quell the use of alcohol and other illicit substances are appropriate in early adolescent samples, as a nontrivial percent of middle school students begin using during this time period. Such intervention attempts may benefit from a focus on increasing perceptions of social support, as this was found to be negatively associated with substance use for both boys and girls. In addition, special attention might be given to boys who report high levels of peer victimization, as interactions between gender and peer victimization indicated the highest reported rates of use for highly victimized boys. Of course, any recommendations for intervention programming should be considered cautiously until findings from the present study are replicated. Future research efforts should consider the role of peers, identify mediating factors, and incorporate other important moderator variables in order to complement and extend the results from this investigation.

Peer relations and substance use-Results from the present study support the claim that there is an association between peer victimization and substance use. However, positive peer relationships were not considered here, except to the extent that school relatedness encompassed relationships with classmates. Peer interactions are particularly salient during the middle school years, when early adolescents begin to rely more on their fellow students than adults for support and approval (Duncan, Duncan, \& Strycker, 2006; Eccles \& Roeser, 2008). Both peer acceptance (Osterman, 2000) and friendship (Ladd, Kochenderfer, \& Coleman, 1997) are negatively associated with peer victimization. Accordingly, they might also relate to lower rates of substance use. This association may depend upon characteristics of the friend or social group; individuals who spend time with deviant peers, for example, tend to participate in more deviant acts themselves (Wang \& Dishion, 2011) and subsequently drink or use substances (Karcher \& Finn, 2005). Clearly, an examination of 
adolescent alcohol and other drug use would be incomplete without considering peers, one of the most influential socializing factors for middle school students.

Potential mediators-The present study did not examine the mechanisms that might explain associations between social factors and early substance use. One promising mediator to consider in future research is drinking motives. Several drinking motives, including conformity and social motives, could reasonably be assumed to relate to social factors (Cox \& Klinger, 1988), particularly for early adolescents (Cooper, 1994). Variables examined in the present study have displayed interesting connections with drinking motives. For instance, social motives are more highly endorsed by adolescent boys than girls (Kuntsche, Knibbe, Gmel, \& Engels, 2006). Evidence also suggests that victimized children or those perceiving low levels of support may drink, smoke, or use marijuana in an attempt to increase their social standing (Balsa, Homer, French, \& Norton, 2011).

In addition to drinking motives, self-blame attributions (Graham \& Juvoven, 1998; Harper, 2011) may mediate the relationship between peer victimization and substance use. Children who are victims of bullying or aggressive behavior may make more self-blaming, stable attributions about themselves, which could lead to increased drinking and substance use (Prinstein, Cheah, \& Guyer, 2005). Finally, stress may be a mediating variable that partially explains the relationship between peer victimization and substance use. Researchers have posited that victimization acts as a stressor, encouraging adolescents to cope by drinking or using other illicit substances (Cooper, Frone, Russell, \& Mudar, 1995; Rusby, Forrester, Biglan, \& Metzler, 2005; Sullivan et al., 2006).

Potential moderators-Gender emerged as an important moderator of the association of between peer victimization and substance use. Gender, however, is just one of many important demographic variables that should be considered when studying youth alcohol and drug use. A student's race or ethnicity, for example, may have interacted with variables examined in the present study. Students from minority groups do not always receive adequate levels of social support in school. Despite research suggesting a positive impact of supportive teacher-student relationships on lowering peer victimization in minority students (Meehan, Hughes, \& Cavell, 2003), teachers often evaluate students from minority groups as having less potential than other students (Weinstein, 2002). Research highlighting the role of race or ethnicity in adolescent substance use could have important implications not only for research but also for intervention efforts.

\section{Limitations}

The current study had several notable limitations that merit discussion. As indicated above, peer relationships were not considered despite their importance in the middle school years. Researchers should consider interactions with peers - both at the dyadic and group levelsin future investigations. In addition, all data were collected at a single time point. This precludes any claims about the directionality of effects and does not rule out the possibility that a third variable could account for the relationship between social factors and substance use. Future studies employing longitudinal or intervention designs may shed light on the directionality of effects between these behaviors. The fact that all data were self-reported 
also raises the possibility of inflated associations due to common method variance; if possible, future studies should attempt to collect objective measures of substance use. Alcohol and other drug use was dichotomized in the current study due to low base rates, not allowing for a comparison of students who have used these agents once or twice and those who use on a fairly regular basis. Future studies should examine differences between groups of students characterized by different quantity and frequencies of use.

Finally, the present study did not evaluate the impact of community and school-level variables on reported alcohol and other drug use, aside from nesting data within schools. Forming a model of adolescent substance use that accounts for the educational and residential community within which students are embedded will undoubtedly provide a more complete understanding of adolescent drinking and drug use (Ennett et al., 1997). While these limitations should be taken in to consideration, the current investigation provides provocative insights into the interplay of risk and preventative factors relating to early onset alcohol and other drug use. Future research and practice should consider the dynamic interplay of such factors in the design of school-based intervention programs.

\section{Acknowledgments}

Funding

The author(s) disclosed receipt of the following financial support for the research, authorship, and/or publication of this article: Funded by AA12171-09 (PI: S.A. Brown), DA021905-01A1 (PI: S.A. Brown).

\section{References}

Aalsma MC, Brown JR. What is bullying? Journal of Adolescent Health. 2008; 43:101-102. [PubMed: 18639781]

Aitken, LS.; West, SG. Multiple regression: Testing and interpreting interactions. Newbury Park, CA: Sage; 1991.

Anderson KG, Brown SA. Middle school drinking: Who, where, and when. Journal of Child and Adolescent Substance Abuse. 2011; 20:48-62.

Anderson KG, Tomlinson KL, Robinson JM, Brown SA. Friends or foes: Social anxiety, peer affiliation, and drinking in middle school. Journal of Studies on Alcohol and Drugs. 2011; 72:6169. [PubMed: 21138712]

Balsa AI, Homer JF, French MT, Norton EC. Alcohol use and popularity: Social payoffs from conforming to peers' behavior. Journal of Research on Adolescence. 2011; 21:559-568. [PubMed: 21860582]

Bandura, A. Social foundations of thought and action: A social-cognitive view. Englewood Cliffs, NJ: Prentice Hall; 1986.

Baraldi AN, Enders CK. An introduction to modern missing data analyses. Journal of School Psychology. 2010; 48:5-37. [PubMed: 20006986]

Bava S, Tapert SF. Adolescent brain development and the risk for alcohol and other drug problems. Neuropsychology Review. 2010; 20:398-413. [PubMed: 20953990]

Beier SR, Rosenfeld WD, Spitalny KC, Zansky SM, Bontempo AN. The potential role of an adult mentor in influencing high-risk behaviors in adolescents. Archives of Pediatrics and Adolescent Medicine. 2000; 154:327-331. [PubMed: 10768667]

Boulton MJ, Underwood K. Bully/victim problems among middle school children. British Journal of Educational Psychology. 1992; 62:73-87. [PubMed: 1558813] 
Bryant AL, Schulenberg J, Bachman JG, O’Malley PM, Johnston LD. Understanding the links among school misbehavior, academic achievement, and cigarette use: A national panel study of adolescents. Prevention Science. 2000; 1:71-87. [PubMed: 11521961]

California Healthy Kids Survey, California Department of Education (Safe and Healthy Kids Program Office), and WestEd (Health and Human Development Department). 2009.

Card NA, Hodges EVE. Peer victimization among schoolchildren: Correlations, causes, consequences, and considerations in assessment and intervention. School Psychology Quarterly. 2008; 23:451461.

Card NA, Stucky BD, Sawalani GM, Little TD. Direct and indirect aggression during childhood and adolescence: A meta-analytic review of gender differences, intercorrelations, and relations to maladjustment. Child Development. 2008; 79:1185-1229. [PubMed: 18826521]

Catalano, RF.; Hawkins, JD. The social development model: A theory of antisocial behavior. In: Hawkins, JD., editor. Delinquency and Crime: Current Theories. New York: Cambridge University Press; 1996. p. 149-197.

Cook CR, Williams KR, Guerra NG, Kim TE, Sadek S. Predictors of bullying and victimization in childhood and adolescence: A meta-analytic investigation. School Psychology Quarterly. 2010; 25:65-83.

Cooper ML. Motivations for alcohol use among adolescents: Development and validation of a fourfactor model. Psychological Assessment. 1994; 6:117-128.

Cooper ML, Frone MR, Russell M, Mudar P. Drinking to regulate positive and negative emotions: A motivational model of alcohol use. Journal of Personality and Social Psychology. 1995; 69:9901005. [PubMed: 7473043]

Cox WM, Klinger E. A motivational model of alcohol use. Journal of Abnormal Psychology. 1988; 97:168-180. [PubMed: 3290306]

Crick NR, Grotpeter JK. Relational aggression, gender, and social-psychological adjustment. Child Development. 1995; 66:710-722. [PubMed: 7789197]

D’Amico E, Ellickson PL, Collins RL, Martino S, Klein DJ. Processes linking adolescent problems to substance-use problems in late young adulthood. Journal of Studies on Alcohol and Drugs. 2005; 66:766-775.

Denny SJ, Robinson EM, Utter J, Fleming TM, Grant S, Milfont TL, Clark T. Do schools influence student risk-taking behaviors and emotional health symptoms? Journal of Adolescent Health. 2011; 48:259-267. [PubMed: 21338897]

Duncan SC, Duncan TE, Strycker LA. Risk and protective factors influencing adolescent problem behavior: A multivariate latent growth curve analysis. Annals of Behavioral Medicine. 2006; 22:103-109. [PubMed: 10962701]

Eccles, JS.; Midgley, C. Stage-environment fit: Developmentally appropriate classrooms for young adolescents. In: Ames, C.; Ames, R., editors. Research on motivation in education. Vol. 3. San Diego, CA: Academic Press; 1989. p. 139-186.

Eccles, JS.; Roeser, RW. Schools, academic motivation, and stage-environment fit: An ecological view of schools and their impact on development during adolescence. In: Lerner, RL.; Steinberg, L., editors. Handbook of adolescent psychology. Hoboken, NJ: John Wiley; 2008. p. 404-434.

Eccles, JS.; Wigfield, A. Schooling's influences on motivation and achievement. In: Danzinger, S.; Waldfogel, J., editors. Securing the future: Investing in children from birth to college. New York, NY: Russell Sage; 2000. p. 153-181.

Ennett ST, Flewelling RL, Lindrooth RC, Norton EC. School and neighborhood characteristics associated with school rates of alcohol, cigarette, and marijuana use. Journal of Health and Social Behavior. 1997; 38:55-71. [PubMed: 9097508]

Eschenbeck H, Kohlmann CW, Lohaus A. Gender differences in coping strategies in children and adolescents. Journal of Individual Differences. 2007; 28:18-26.

Farmer TW, Lines MM, Hamm JV. Revealing the invisible hand: The role of teachers in children's peer experiences. Journal of Applied Developmental Psychology. 2011; 32:247-256.

Feshbach ND. Sex differences in children's modes of aggressive responses towards outsiders. MerrillPalmer Quarterly. 1969; 15:249-258. 
Furrer C, Skinner E. Sense of relatedness as a factor in children's academic engagement and performance. Journal of Educational Psychology. 2003; 95:148-162.

Goodenow C. Classroom belonging among early adolescent students: Relationships to motivation and achievement. Journal of Early Adolescence. 1993; 13:21-43.

Graham S, Juvoven J. Self-blame and peer victimization in middle school: An attributional analysis. Developmental Psychology. 1998; 34:587-599. [PubMed: 9597367]

Guttmannova K, Bailey JA, Hill KG, Lee JO, Hawkins JD, Woods ML, Catalano RF. Sensitive periods for adolescent alcohol use initiation: Predicting the lifetime occurrence and chronicity of alcohol problems in adulthood. Journal of Studies on Alcohol and Drugs. 2011; 72:221-231. [PubMed: 21388595]

Harper BD. Parents' and children's beliefs about peer victimization: Attributions, coping responses, and child adjustment. Journal of Early Adolescence. 2012; 32:387-413.

Harrist AW, Bradley KD. You can't say you can't play: Intervening in the process of social exclusion in the kindergarten classroom. Early Childhood Research Quarterly. 2003; 18:185-205.

Johnston, LD.; O’Malley, PM.; Bachman, JG.; Schulenberg, JE. Monitoring the future national survey results on drug use, 1975-2005. Volume I: Secondary school students. Bethesda, MD: National Institute on Drug Abuse; 2006.

Johnston, LD.; O'Malley, PM.; Bachman, JG.; Schulenberg, JE. Marijuana use is rising; ecstasy use is beginning to rise; and alcohol use is declining among U.S. teens. Ann Arbor: University of Michigan News Service; 2010 Dec 14. Retrieved from http://www.monitoringthefuture.org

Karcher MJ, Finn L. How connectedness contributes to experimental smoking among rural youth: Developmental and ecological analyses. Journal of Primary Prevention. 2005; 26:25-36. [PubMed: 15976928]

Kindermann TA. Commentary: The invisible hand of the teacher. Journal of Applied Developmental Psychology. 2011; 32:304-308.

Kuntsche E, Knibbe R, Gmel G, Engels R. Who drinks and why? A review of socio-demographic, personality, and contextual issues behind the drinking motives in young people. Addictive Behaviors. 2006; 31:1844-1857. [PubMed: 16460883]

Ladd GW, Kochenderfer BJ, Coleman CC. Classroom peer acceptance, friendship, and victimization: Distinct relational systems that contribute uniquely to children's school adjustment. Child Development. 1997; 68:1181-1197. [PubMed: 9418233]

Larson RW, Angus RM. Adolescents' development of skills for agency in youth programs: Learning to think strategically. Child Development. 2011; 82:277-294. [PubMed: 21291442]

Leff SS, Waasdorp TE, Crick NR. A review of existing relational aggression programs: Strengths, limitations, and future directions. School Psychology Review. 2010; 39:508-535. [PubMed: 21666876]

Lifrak PD, McKay JR, Rostain A, Alterman AU, O’Brien CP. Relationships of perceived competencies, perceived social support, and gender to substance use in young adolescents. Journal of the American Academic of Child and Adolescent Psychiatry. 1997; 36:933-940.

Lubans DR, Plotnikoff RC, Lubans NJ. A systematic review of the impact of physical activity programs on social and emotional well-being in at-risk youth. Child and Adolescent Mental Health. 2012; 17:2-13.

McGee E, Valentine C, Schulte MT, Brown SA. Peer victimization and alcohol involvement among adolescents self-selecting into a school-based alcohol intervention. Journal of Child and Adolescent Substance Abuse. 2011; 20:253-269.

Meehan BT, Hughes JN, Cavell TA. Teacher-student relationships as compensatory resources for aggressive children. Child Development. 2003; 74:1145-1157. [PubMed: 12938710]

Morgan ML, Vera EM, Gonzales RR, Conner W, Vacek KB, Coyle LD. Subjective well-being in urban adolescents: Interpersonal, individual, and community influences. Youth and Society. 2011; 43:609-634.

Murray-Harvey R, Slee PT. School and home relationships and their impact on school bullying. School Psychology International. 2010; 31:271-295. 
Nansel TR, Craig W, Overpeck MD, Saluja G, Ruan WJ. Cross-national consistency in the relationship between bullying behaviors and psycho-social adjustment. Archives of Pediatrics and Adolescent Medicine. 2004; 158:730-736. [PubMed: 15289243]

Nansel TR, Overpeck M, Pilla RS, Ruan WJ, Simons-Morton B, Scheidt P. Bullying behaviors among US youth: Prevalence and association with psychosocial adjustment. Journal of the American Medical Association. 2001; 285:2094-2100. [PubMed: 11311098]

Nixon K, Morris SA, Liput DJ, Kelso ML. Roles of neural stem cells and adult neurogenesis in adolescent alcohol use disorders. Alcohol. 2010; 44:39-56. [PubMed: 20113873]

O’Brennan LM, Furlong MJ. Relations between students' perceptions of school connectedness and peer victimization. Journal of School Violence. 2010; 9:375-391.

Oelsner J, Lippold MA, Greenberg MT. Factors influencing the development of school bonding among middle school students. Journal of Early Adolescence. 2011; 31:463-487. [PubMed: 22427716]

Olweus, D. Peer harassment: A critical analysis and some important issues. In: Juvoven, J.; Graham, S., editors. Peer harassment in school: The plight of the vulnerable and victimized. New York, NY: Guilford; 2001. p. 3-20.

Osterman KF. Students' need for belonging in the school community. Review of Educational Research. 2000; 70:323-367.

Paquette JA, Underwood MK. Gender differences in young adolescents' experiences of peer victimization: Social and physical aggression. Merrill-Palmer Quarterly. 1999; 45:242-266.

Patrick H, Ryan AM, Kaplan A. Early adolescents' perceptions of the classroom social environment, motivational beliefs, and engagement. Journal of Educational Psychology. 2007; 99:83-98.

Peleg-Oren N, Saint-Jean G, Cardenas GA, Tammara H, Pierre C. Drinking alcohol before age 13 and negative outcomes in late adolescence. Alcoholism: Clinical and Experimental Research. 2009; 33:1966-1972.

Perry DG, Pauletti RE. Gender and adolescent development. Journal of Research on Adolescence. 2011; 21:61-74.

Pouwelse M, Bolman C, Lodewijkx H, Spaa M. Gender differences and social support: Mediators or moderators between peer victimization and depressive feelings? Psychology in the Schools. 2011; 48:800-814.

Preacher KJ, Curran PJ, Bauer DJ. Computational tools for probing interaction effects in multiple linear regression, multilevel modeling, and latent curve analysis. Journal of Educational and Behavioral Statistics. 2006; 31:437-448.

Prinstein MJ, Cillessen AHN. Forms and functions of adolescent peer aggression associated with high levels of peer status. Merrill-Palmer Quarterly. 2003; 49:310-342.

Prinstein MJ, Cheah CSL, Guyer AE. Peer victimization, cue interpretation, and internalizing symptoms: Preliminary concurrent and longitudinal findings for children and adolescents. Journal of Clinical Child \& Adolescent Psychology. 2005; 34:11-24. [PubMed: 15677277]

Pronk RE, Zimmer-Gembeck MJ. It's "mean," but what does it mean to adolescents? Relational aggression described by victims, aggressors, and their peers. Journal of Adolescent research. 2010; 25:175-204.

Reddy R, Rhodes JE, Mulhall P. The influence of teacher support on student adjustment in the middle school years: A latent growth curve study. Development and Psychopathology. 2003; 15:119-138. [PubMed: 12848438]

Rhodes JE, Grossman JB, Resch NL. Agents of change: Pathways through which mentoring relationships influence adolescents' academic adjustment. Child Development. 2000; 71:16621671. [PubMed: 11194264]

Rodkin, PC.; Ryan, AM. Child and adolescent peer relations in educational context. In: Harris, KR.; Graham, S.; Urdan, T.; Graham, S.; Royer, JM.; Zeidner, M., editors. APA educational psychology handbook. Vol. 2. Washington, DC: American Psychological Association; 2012. p. 554

Rueger SY, Malecki CK, Demaray MK. Gender differences in the relationship between perceived social support and student adjustment during early adolescence. School Psychology Quarterly. 2008; 23:496-514. 
Rueger SY, Malecki CK, Demaray MK. Relationship between multiple sources of perceived social support and psychological and academic adjustment in early adolescence: Comparisons across gender. Journal of Youth and Adolescence. 2010; 39:47-61. [PubMed: 20091216]

Rusby JC, Forrester KK, Biglan A, Metzler CW. Relationships between peer harassment and adolescent problem behaviors. Journal of Early Adolescence. 2005; 25:453-477.

Simons-Morton B, Crump AD, Haynie DL, Saylor KE. Student-school bonding and adolescent problem behavior. Health Education Research. 1999; 14:99-107. [PubMed: 10537951]

Stearns E, Glennie EJ. Opportunities to participate: Extracurricular activities' distribution across and academic correlates in high schools. Social Science Research. 2010; 39:296-310.

Stipek D, MacIver D. Developmental change in children's assessment of intellectual competence. Child Development. 1989; 60:521-538.

Sullivan TN, Farrell AD, Kliewer W. Peer victimization in early adolescence: Association between physical and relational victimization and drug use, aggression, and delinquent behaviors among urban middle school students. Development and Psychopathology. 2006; 18:119-137. [PubMed: 16478555]

Swahn MH, Bossarte RM. Gender, early alcohol use, and suicide ideation and attempts: Findings from the 2005 youth risk behavior survey. Journal of Adolescent Health. 2007; 41:175-181. [PubMed: 17659222]

Swahn MH, Donovan JE. Predictors of fighting attributed to alcohol use among adolescent drinkers. Addictive Behaviors. 2005; 30:1317-1334. [PubMed: 16022929]

Sznitman SR, Dunlop SM, Nalkur P, Khurana A, Romer D. Student drug testing in the context of positive and negative school climates: Results from a national survey. Journal of Youth and Adolescence. 2011; 41:146-155. [PubMed: 21461908]

Tharp-Taylor S, Haviland A, D'Amico EJ. Victimization from mental and physical bullying and substance use in early adolescence. Addictive Behaviors. 2009; 34:561-567. [PubMed: 19398162]

Tomlinson KL, Brown SA. Self-medication or social learning? A comparison of models to predict early adolescent drinking. Addictive Behaviors. 2012; 37:179-186. [PubMed: 22055793]

Topper LR, Castellanos-Ryan N, Mackie C, Conrod PJ. Adolescent bullying victimization and alcohol-related problem behavior mediated by coping drinking motives over a 12 month period. Addictive Behaviors. 2011; 36:6-13. [PubMed: 20869813]

Wall J, Covell K, MacIntyre PD. Implications of social supports for adolescents' education and career aspirations. Canadian Journal of Behavioral Science. 1999; 31:63-71.

Wang MT, Dishion TJ. The trajectories of adolescents' perceptions of school climate, deviant peer affiliation, and behavioral problems during the middle school years. Journal of Research on Adolescence. 2012; 22:40-53. [PubMed: 22822296]

Weinstein, RS. Reaching higher: The power of expectations in schooling. Cambridge, MA: Harvard University Press; 2002.

Wentzel KR. Student motivation in middle school: The role of perceived pedagogical caring. Journal of Educational Psychology. 1997; 89:411-419.

Wentzel KR. Social relationships and motivation in middle school: The role of parents, teachers, and peers. Journal of Educational Psychology. 1998; 90:202-209.

Wentzel KR, Battle A, Russell SL, Looney LB. Social supports from teachers and peers as predictors of academic and social motivation. Contemporary Educational Psychology. 2010; 35:193-202.

Xie H, Drabick DAG, Chen D. Developmental trajectories of aggression from late childhood through adolescence: Similarities and differences across gender. Aggressive Behavior. 2011; 37:387-404. [PubMed: 21748751]

\section{Biographies}

Stephanie V. Wormington, is a research assistant in the Department of Psychology at Reed College, where she received her bachelor of arts degree in 2010. Her research interests

include school-related factors, particularly academic motivation and social relationships, that impact students' functioning both in and outside the classroom. 
Kristen G. Anderson, is an assistant professor of psychology and the principal investigator of the Adolescent Health Research Program at Reed College. She obtained her PhD in clinical psychology from the University of Kentucky. Her research focuses on adolescent substance use, decision making, and the developmental psychopathology of addictions from late childhood through emerging adulthood.

Kristin L. Tomlinson, is a graduate student of developmental psychology at the University of California, San Diego. She received her master's of arts degree in psychology from UCSD. Her research interests include identifying developmental risk factors for early onset substance use and abuse, with a special focus on psychiatric symptoms that emerge during adolescence.

Sandra A. Brown, is vice chancellor of research at the University of California, San Diego, where she is also a professor of psychology and psychiatry. She received her PhD from Wayne State University. Her research focuses on the emergence and remission of alcohol and drug problems in the context of life development as well as developmentally tailored addiction interventions. 

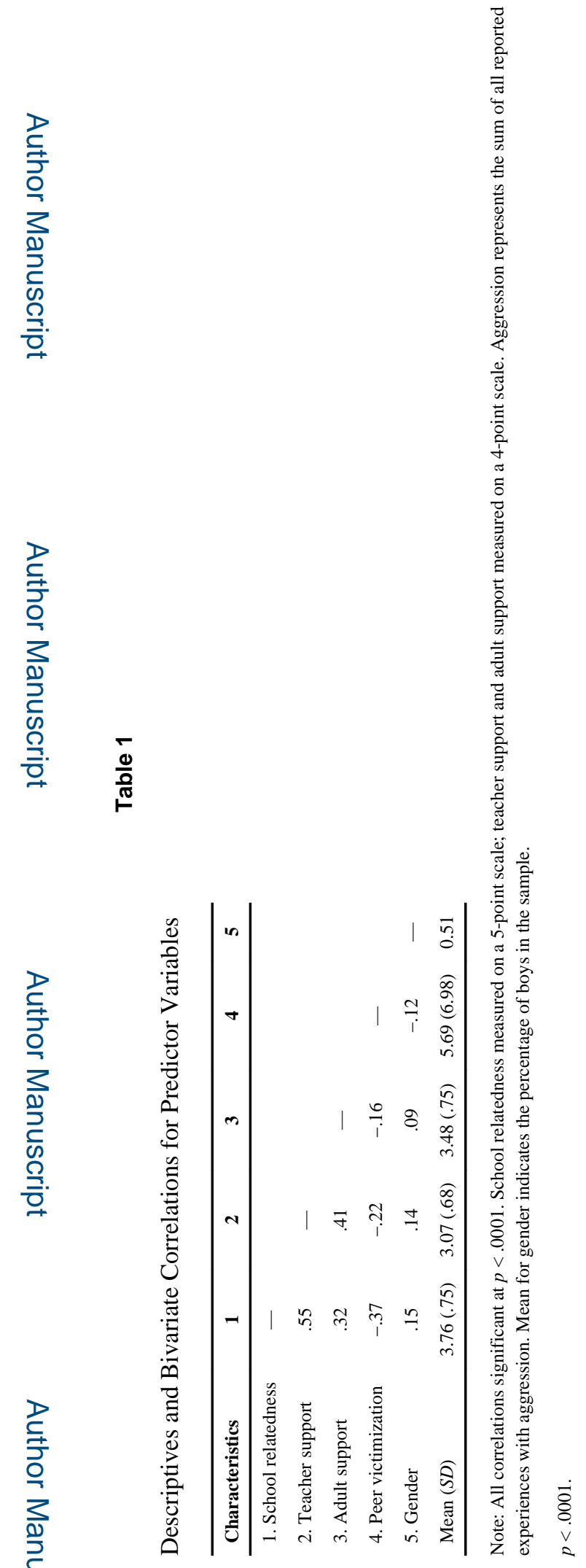

J Early Adolesc. Author manuscript; available in PMC 2015 August 18. 

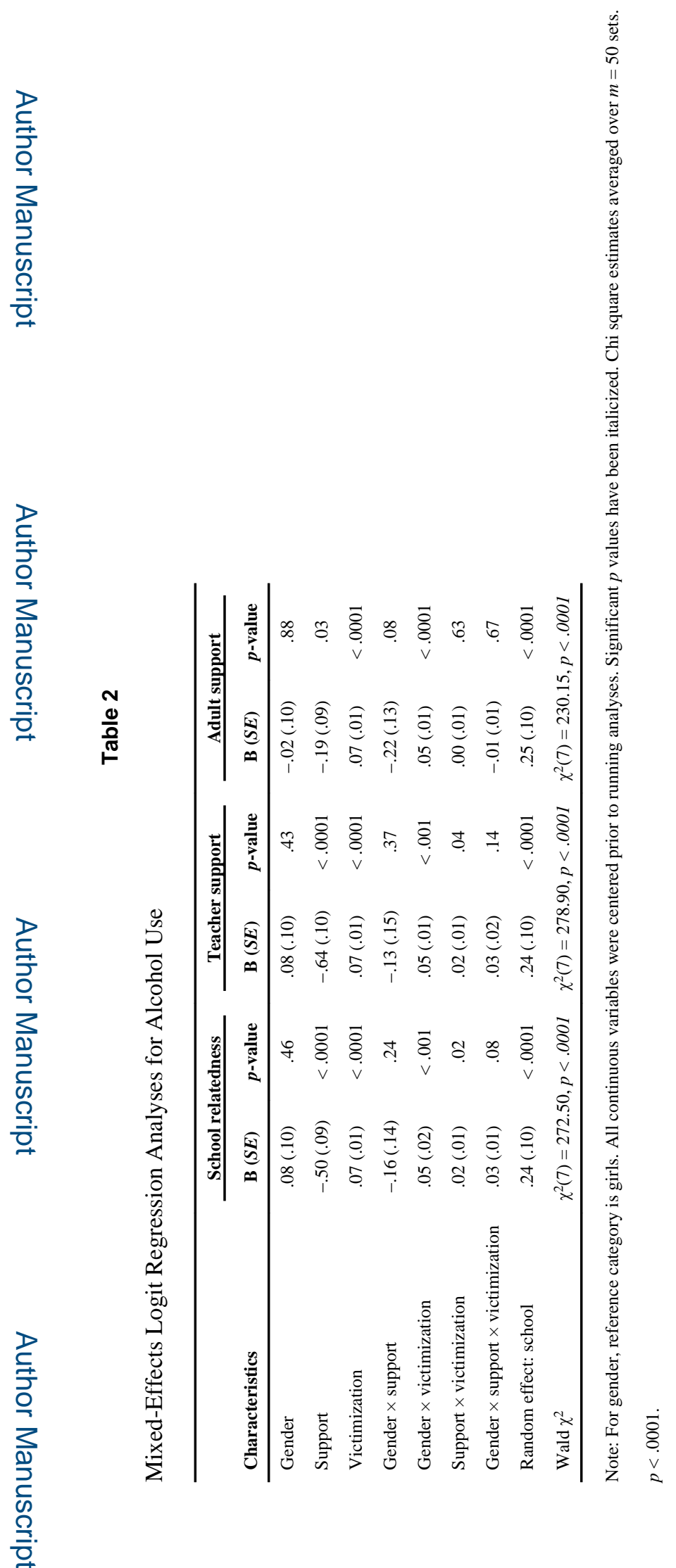

J Early Adolesc. Author manuscript; available in PMC 2015 August 18. 


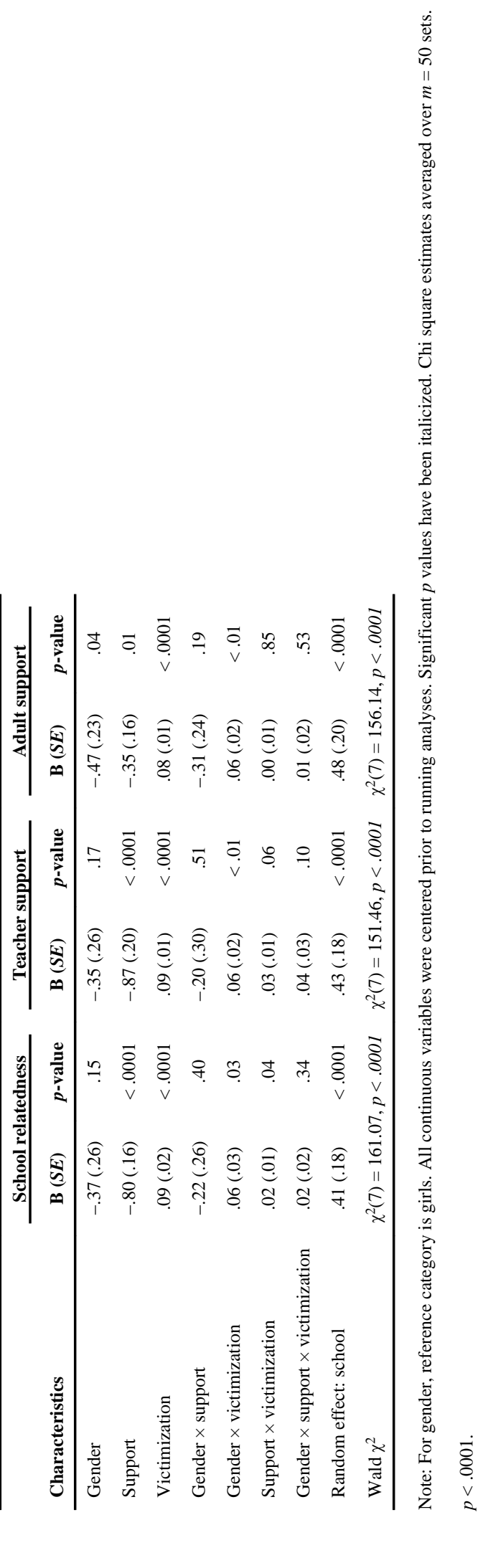



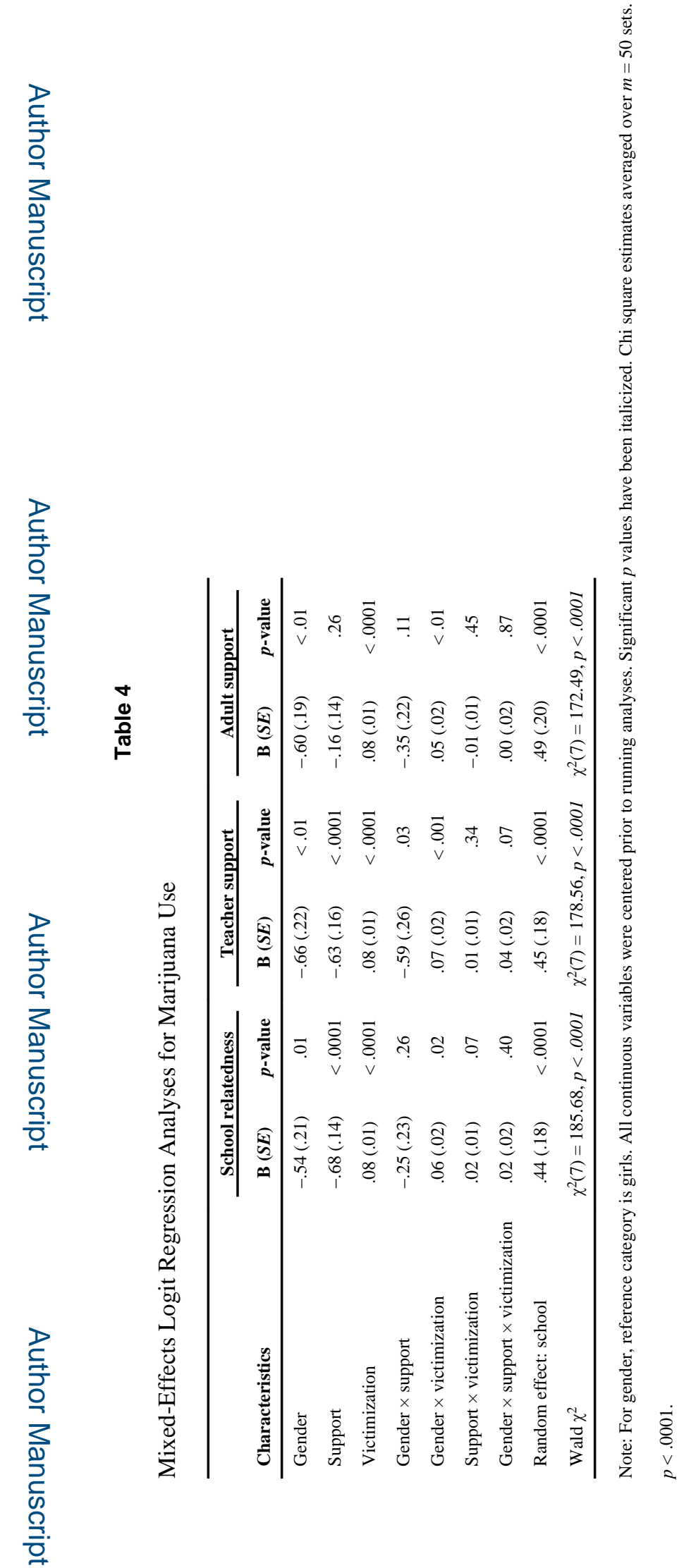

J Early Adolesc. Author manuscript; available in PMC 2015 August 18. 